\title{
Narrativas das mulheres das classes populares: modos de subjetivação e educação escolar
}

\author{
Modes of subjetctivity and school education in the narrative of common-class women
}

\author{
Narrativas de mujeres de clases populares: modos de subjetivación y \\ educación de las escuelas
}

ANDERSON FERRARI*

ZAINE SIMAS MATTOS**

\begin{abstract}
$\diamond$
RESUMO

Este texto é resultado de uma pesquisa que tem como foco de análise os atravessamentos de classe e gênero nos modos de subjetivação de mulheres das classes populares. O campo de investigação é uma escola pública municipal que atendia e atende mulheres das classes populares, de maneira que foi possível trabalhar com duas gerações de famílias chefiadas por mulheres. Trabalhando com entrevistas narrativas, a pesquisa tem como foco os relatos que ressaltam as vivências delas nos modos de serem mulheres, mães, ex-alunas, representantes das classes populares e de gerações distintas no que tange às suas relações com a educação escolar. Para isso, assumiu-se uma questão motivadora, que se buscou responder neste texto: de que modos as mulheres narram as suas relações com a educação escolar e como essas relações são atravessadas por classe e gênero? Este, o referencial teórico-metodológico do qual este artigo se aproxima, privilegiando os estudos foucaultianos por um viés pós-estruturalista.
\end{abstract}

Palavras-chave: Mulheres. Modos de subjetivação. Educação escolar. Classes populares.

\begin{abstract}
This text is the result of a research that has as its focus of analysis the class and gender crossings in the modes of subjectivity of common-class women. The research field is a municipal public school that attended and attends to common-class women, so it was possible to work with two generations of families headed by women. Working with narrative interviews, we are interested in the narratives that inform us of these crossings between modes of constituting women, mothers and former students, representatives of the common classes and of different generations, with respect to their relationship with schooling. In doing so, we assume a motivating question, which we seek to answer in this text: in what ways do women narrate their relationship with the school and how these relationships are crossed by class and gender? The theoretical and methodological framework of research emphasizes Foucaultian Studies with a post-structuralist bias.
\end{abstract}

Keywords: Women. Modes of subjectivity. Schooling. Common classes.

\section{RESUMEN}

Este texto es el resultado de una investigación que tiene como objetivo el análisis de los cruces de clase y de género en los modos de subjetivación de las mujeres de las clases populares. El campo de investigación es una escuela pública que cumplió y cumple con las mujeres de las clases populares, de manera que foe posible trabajar con dos generaciones de familias encabezadas por mujeres. Trabajando con entrevistas narrativas, estamos interesados en las narraciones que nos dicen de estos cruces entre los modos de se constituyr mujeres, madres, ex-alumnas, representantes de las clases populares y de diferentes generaciones, con respecto a sus relaciones con la escolarización. Así que, asumimos un tema motivador, que buscamos responder en este texto: ¿de qué manera las mujeres narran sus relaciones con la escuela y cómo esas relaciones están cruzados por clase y género? El marco teórico de la investigación privilegia los estudios de Foucault para un sesgo post-estructuralista.

Palabras clave: Mujeres. Modos de subjetividad. Educación. Clases populares.

\footnotetext{
* Professor da Faculdade de Educação e do Programa de Pós-Graduação em Educação da Universidade Federal de Juiz de Fora (UFJF). Doutor em Educação pela Universidade Estadual de Campinas (2005).E-mail: <aferrari13@globo.com>.

**Doutora em Educação pelo Programa de Pós-Graduação em Educação (UFJF). Mestre em Educação pela Universidade Católica de Petrópolis. Assistente Social.E-mail: <zainemattos@terra.com.br>.
} 


\section{INTRODUÇÃO}

Este artigo é resultado de uma pesquisa que analisou os atravessamentos de classe e gênero nos modos de subjetivação de mulheres das classes populares. Trabalhar com esses vieses é colocar sob investigação os sujeitos e, mais especificamente, é responder à questão: "Como nos tornamos o que somos?". Os estudos feministas vêm demostrando a impossibilidade de pensar a mulher como categoria homogênea, o que implica colocar em discussão os atravessamentos que constituem os gêneros. Esses atravessamentos entre construção de gênero e classe foram identificados no cotidiano de uma escola pública municipal na cidade de Juiz de Fora/MG como marcadamente femininos. Havia um corpo docente composto somente por mulheres, que atendia e atende mulheres das classes populares. Mas um movimento em especial começou a chamar a atenção: as meninas/alunas que se tornavam mães e voltavam à escola para matricular seus(uas)filhos(as). Nesse sentido, havia nessa escola, campo da investigação, um número de mães que eram, ao mesmo tempo, ex-alunas da escola.

Esse contexto despertou a curiosidade no sentido foucaultiano:

(...) o único tipo de curiosidade que, de qualquer forma, vale a pena ser praticada como um pouco de obstinação: não aquela que busca se assimilar o que convém conhecer, mas a que permite desprender-se de si mesmo. De que valeria a obstinação do saber se ela apenas garantisse a aquisição de conhecimentos, e não, de uma certa maneira e tanto quanto possível, o extravio daquele que conhece? Há momentos na vida em que a questão de saber se é possível pensar de forma diferente da que se pensa e perceber de forma diferente da que se vê é indispensável para continuar a ver ou a refletir (FOUCAULT, 2006, p. 196-197).

Movidos por esse interesse, optou-se por escutar as ex-alunas mães, que falavam de uma ausência da figura masculina, fossem pais, maridos ou companheiros $\mathrm{E}$ expressavam uma realidade de comunidade feminina que não estava somente na escola, mas na vida. De maneira que se acabou trabalhando com famílias chefiadas por mulheres, o que ampliava os compromissos delas com a educação dos(as) filhos(as). Narrativas que foram construídas e que refletem esses atravessamentos entre os modos de se constituírem mulheres, mães, ex-alunas, representantes das classes populares, no que diz respeito às suas relações com a educação escolar. Para tanto, assumiu-se uma questão motivadora, que se buscou responder neste texto: de que modos as mulheres narram as suas relações com a educação escolar e como essas relações são atravessadas por classe e gênero?
O material empírico foi construído a partir de entrevistas narrativas em que as próprias mulheres se narram e, com isso, significam as suas experiências de vida, entrelaçadas aos processos de escolarização. A pesquisa se organizou a partir de um recorte gestacional, trabalhando com ex-alunas - Flávia (23 anos, dois filhos na escola e parou de estudar no $7 \underline{0}$ ano do ensino fundamental), Vanessa (31 anos, dois filhos na escola e parou de estudar no 5o ano do ensino fundamental), Cláudia (27 anos, uma filha na escola e completou os estudos com supletivo do ensino médio) e Cristina (23 anos, sem filhos e estudante de Administração) ${ }^{1}$, bem como com as mães dessas ex-alunas: D. Lourdes (50 anos, mãe de Cláudia e irmã/mãe de Vanessa. Estudou até o 4 o ano do ensino fundamental) e D. Cristiana (63 anos, mãe de Cristina, cursou EJA até o $2^{\circ}$ ano do ensino fundamental). Com interesse na materialidade das narrativas, inspirou-se nos estudos foucaultianos como referencial teórico-metodológico para trabalhar com os discursos que constroem as categorias classe e gênero. Segundo Foucault (2006), todos são sujeitos de experiência num processo de dessubjetivação/subjetivação. Por tudo isso, as falas das mulheres mães ex-alunas convidam a pensar como vão se constituindo experiências/modos de subjetivação, formações discursivas e práticas que as posicionam em relação à educação escolar.

Pode-se dizer que, ao final, um aspecto se destacou: a percepção da escolarização como um imperativo na vida, como um modo de "ser alguém na vida". E, tanto a realização desse imperativo quanto o seu "insucesso" se mostraram atuantes nos modos de subjetivação dessas mulheres em especial. Num olhar mais atento, percebe-se que o corte geracional apontou para mudanças nas formas de compreender a educação escolar que, a princípio, era vista como um privilégio de poucos(as), passando a ser um direito e chegando, na atualidade, a ser percebida como um imperativo para a inserção social. A valorização da escola e do processo de escolarização era afetada pelas contingências de classe, trazendo a maternidade, a sobrevivência diária e as construções de masculinidades e feminilidades como questões que interferem na relação com a educação escolar.

\section{MOdOS DE SUBJETIVAÇÃo E A RELAÇÃo COM O SUCESSO/INSUCESSO ESCOLAR}

A educação escolar é produzida pelos discursos da mídia, das políticas públicas, das famílias e demais instituições como sendo algo imprescindível na vida das pessoas. Diferentes instituições que falam sobre educação

\footnotetext{
Os nomes utilizados na pesquisa foram escolhidos pelas próprias participantes para resguardar-lhes o anonimato.
} 
e formam um conjunto que impacta as possibilidades de subjetivação, uma vez que reforçam a importância e a necessidade de investimento na educação dos sujeitos. Pretende-se dizer com isso que os discursos, como um conjunto de enunciados (FOUCAULT, 2008), constituem as pessoas, sendo resultados destes. No entanto, estão constituídos de um número limitado de enunciados, de maneira que se pode pensar a respeito das condições de existência daquilo que é dito em determinado tempo e contexto. Falar dessa produção significa pensar em como ela incide na forma como as mulheres se percebem e se posicionam na sociedade. A interrupção dos estudos ou mesmo o insucesso nesse campo aparecem, nas narrativas, como algo que não deveria acontecer. $\mathrm{O}$ insucesso interfere na construção da identidade das mulheres participantes da pesquisa. Algumas o atribuem a si próprias, como se elas não tivessem se esforçado o bastante para obterem êxito na educação escolar. A estrutura do ensino e as diferenças de classe são invisibilizadas.

Essa defesa do processo de escolarização para todos e todas estabelece certo nexo entre o pensamento e os sujeitos, fundando um quadro ordenado de identidades e diferenças com base no que se diz e no que se ouve, ou seja, dos sentidos que se atribui à educação. A culpabilização, o esforço, a dedicação e a concentração nos estudos impactam os sujeitos. Flávia se aproxima desse tipo de construção discursiva se colocando como a responsável por seu insucesso na educação escolar: "É, porque, antes, eu tinha que ter levado mais a vida a sério, né? Mas antes eu brincava muito, agora, hoje que eu vejo o aperto que eu passo agora". Em outra passagem, acrescenta: "Porque o que eu perdi, hoje, agora eu penso: que hoje eu deixei meus estudos para lá, de lado, fui brincando muito na escola".

A culpabilidade assumida também aparece na fala de D. Lourdes, que "não conseguia aprender" e essa "dificuldade" foi assumida como sendo de sua exclusiva responsabilidade. Não encontra outras respostas para, mesmo gostando da escola, não conseguir aprender:

\footnotetext{
"Eu gostava da escola. Mas na hora de fazer provas, estas coisa, aí eu oh..., deixava de lado. Eu fazia o que eu sabia, e depois punha a prova escondida, assim, debaixo da carteira. Eu gostava de aprender, mas eu acho que eu não tinha cabeça assim para aprender. Eu acho que era isso, eu não aprendia, aí fui cansando de ir para a escola e não aprender. Aí chegou a quarta série, pronto, acabou." (D. Lourdes)
}

Não é de qualquer educação e de qualquer mulher que se está falando e que elas falam. Os assuntos educação e mulher que aparecem nas falas são fruto de "jogos de linguagem" que definem o que sobre elas pode ser falado, em que circunstâncias, por quem, com que limites. Pois são essas limitações às possibilidades de enunciação que Foucault define como os "regimes de verdade" (1993). Os discursos são práticas que sistematicamente constroem os objetos dos quais falam. Ao falarem das relações com a educação e com a escola, vão construindo "a" educação e "a" escola, assim como vão se constituindo em relação a elas.

Cada sociedade tem seu regime de verdade, sua 'política geral' de verdade: isto é, os tipos de discurso que aceita e faz funcionar como verdadeiros; os mecanismos e instâncias que permitem distinguir entre sentenças verdadeiras e falsas, os meios pelos quais cada um deles é sancionado (FOUCAULT, 1993, p. 12).

D. Cristiana fala da mesma dificuldade em compreender determinados conteúdos, seguindo a leitura de localizá-la no sujeito, levando-a a abandonar a escola: "Pois é... matemática então, não entrava na minha cabeça. Aí eu falava: Ah, não vou estudar mais não. Entendeu? Aí eu parei”. D. Cristiana, porém, chega a perceber que seus "problemas" de aprendizagem podem estar associados à falta de oportunidade em estudar quando criança: "Era assim, muito difícil para aprender, né? Porque a gente não teve aquela oportunidade quando era pequena, né?". O que se consegue entender como "problemas", ou melhor, o que se torna, para cada um, problema ou tema particular só parece possível através de possibilidades que a linguagem torna disponíveis. Ao falarem das relações com a escolarização, as mulheres entram num regime de "vizibilidade", constituindo-se em resultados da "verdade": da "verdade" da educação, da "verdade" do que é escola e da "verdade de si".

Em nenhuma dessas narrativas, as mulheres conseguem trazer à tona outras problematizações capazes de pensar sobre o porquê de ficar "brincando na escola", "de não levar a escola a sério", de não aprender certos conteúdos, de não ter estudado na idade certa. A "culpa" parece ser internalizada como um problema pessoal que só poderia ser resolvido com o afastamento da escola.

Apesar de a educação se constituir em um direito social, assegurado por leis e decretos, e em um imperativo na sociedade atual, este não se mostra da mesma forma para todos(as). Alguns(mas) têm de lutar mais que outros(as) para sua concretização. As escolas e as condições sociais e econômicas de cada um interferem nas formas e modos de alcançar plenamente esse direito.

Dentre as participantes da pesquisa, são Cláudia e Cristina que conseguem apontar para a qualidade da educação e para as relações de classe como fatores que podem incidir na relação das pessoas com a educação escolar. Suas narrativas evidenciam a baixa qualidade do ensino oferecido nas escolas em que estudaram, além de 
ratificarem diferenças de qualidade em relação às escolas destinadas a outras classes sociais.

“[...] praticamente do que eu estudei eu não me lembro mais. Se perguntar alguma coisa da $8^{a}$ série eu não me lembro mais, eu não sei como eu tirei o segundo grau. Porque tem muita coisa assim, se colocar eu ali pra fazer, eu não sei nem como é que começa. E, assim, eu acho que consegui o diploma, mas eu não achei que eu, que eu, que eu, assim, aprendi.” (Cláudia)

D. Cristina aponta, ainda, para as condições sociais e econômicas a que esteve exposta, atribuindo a estas a interferência na aquisição de uma educação escolar que lhe fornecesse condições de seguir seus estudos e ingressar na universidade:

“Então. Eu acho que, se a escola pública fosse um pouquinho melhor, teria sido mais fácil. (...) Porque eu tive que estudar o dobro do que o pessoal estuda. Estudei muito para eu passar. (...) Ah, se eu tivesse um dinheiro para pagar um cursinho, seria melhor, né? Fazer um curso de Inglês..." (Cristina)

Ao mesmo tempo em que entendem e reconhecem que a escola é importante, também identificam que esta tem problemas e que pode, de certa forma, dificultar o cumprimento de uma educação escolar de qualidade. Nesse sentido, diferentemente da própria mãe, Cláudia não assume para si a culpa pelo seu fracasso escolar; sabe que se esforçou para estudar, mas esbarrou na qualidade da educação que lhe foi oferecida. O discurso da escola como algo importante e fundamental para a transformação das pessoas e de suas vidas permanece. No entanto, o que se modifica de uma geração para a outra é a leitura que se faz do "sucesso" ou "fracasso" nesse campo. Os significados atribuídos à escolarização são resultados de construção social e histórica, de maneira que são sustentados por discursos que nem sempre são homogêneos.

$\mathrm{O}$ fato de apenas duas das entrevistadas perceberem a qualidade do ensino e suas condições de classe como interferindo na adequação/inadequação ao sistema escolar convida a se pensar a respeito do viés de geração. Cláudia e Cristina são de uma geração que não somente vive um tempo em que a escola é construída como algo necessário e do qual não se pode fugir, mas também um momento em que se problematizam ou mesmo se denunciam as condições dessa escolarização nos mais diversos meios de comunicação. Por outro lado, D. Cristiana e D. Lourdes, as mães das ex-alunas, não manifestam essas problematizações, o que pode estar atrelado aos discursos construídos em seus tempos de infância, que não lhes possibilitaram questionar a educação pública de qualidade como um direito de todos/as. Conforme Foucault (2010, p. 8-9):
[...] em toda sociedade a produção de discurso é ao mesmo tempo controlada, selecionada, organizada e redistribuída por certo número de procedimentos que têm por função conjurar seus poderes e perigos, dominar seu acontecimento aleatório, esquivar sua pesada e temível materialidade.

Isso porque, nos dias atuais, a geração de discursos sobre a produtividade da escola é controlada, organizada e redistribuída. O que ocorre através de procedimentos propagados pelas mídias, de debates organizados por movimentos sociais, de falas cotidianas que falam dos poderes da educação na vida das pessoas e de perigos que enfrentam as pessoas nesses processos de escolarização.

Os discursos atuais apontam para a escolarização como um caminho para "ser alguém na vida", como algo importante para cada um em particular e para o todo da sociedade. É como se dissesse para as pessoas que, se elas não se escolarizaram "adequadamente", não são "dignas de ser", "não são nada na vida". Trata-se de um enunciado que destitui o sujeito de ser, se ele(a) não é alguém, o que ele(a) é então? Não existem outras formas de ser para além da educação escolar? As pessoas que "são alguém na vida" tiveram o mesmo ponto de partida daquelas que "não são alguém na vida"?

A partir do recorte geracional, é possível perceber a contingência das compreensões que envolvem a educação escolar. Percebê-la como um direito e/ou imperativo, assim como uma avaliação das causalidades do insucesso escolar, como sendo um problema pessoal ou atribuído a fatores sociais e políticos, são possibilidades que surgem a partir de condições de emergência que tornam possíveis um entendimento e não outro.

No final da década de 1950 e início da década de 1970, época em que as mães das ex-alunas deveriam estar em processo de escolarização, a educação ainda não era percebida por todos(as) como um direito e muito menos como um imperativo. A questão da qualidade da educação oferecida às classes populares não se mostrava como uma questão para essas mulheres. A esse respeito, Foucault (2010, p. 9) pontua: "Sabe-se bem que não se tem o direito de dizer tudo, que não se pode falar de tudo em qualquer circunstância, que qualquer um, enfim, não pode falar de qualquer coisa". Pensando com Foucault (2010), pode-se dizer que não havia condições para que elas pudessem problematizar o que se passava. $\mathrm{O}$ questionamento da qualidade do ensino não se mostrava favorável; talvez elas nem soubessem do direito à educação pública e gratuita. À D. Cristiana, cabia aceitar o fato de não ter podido estudar quando criança e, mais tarde, de ter retornado e abandonado a escola quando não mais "conseguia aprender matemática". À D. Lourdes, cabia aceitar que "não tinha cabeça para aprender" e o fato de ter parado de estudar após múltiplas repetências. 
O enunciado "ser alguém na vida" é recorrente nas narrativas. Acreditando-se que os discursos e as relações de poder constroem os sujeitos (FOUCAULT, 2008) a partir das experiências vividas por eles, pode-se pensar que esse enunciado atua na constituição dessas mulheres, afetando a sua relação com a escola e com os modos de se relacionar com o mundo. Não se está afirmando que este constrói as mulheres como aquelas que têm de "ser alguém na vida", mas que suas subjetividades são produzidas nessa tensão entre o "assujeitamento" e a resistência a ele (FOUCAULT, 1984). As mulheres são chamadas a se constituírem na educação escolar para encontrarem um lugar de "sucesso" na sociedade, que no contexto das falas se refere a ter um bom emprego, retorno econômico e prestígio social. Diante desse enunciado, as mulheres atribuem significados e sentidos ao que são ou que julgam que deveriam ser. Constroem-se como uma pessoa que "é alguém na vida" ou como aquela que "não conseguiu ser alguém na vida".

Essas mulheres criaram representações sobre o mundo, produzindo realidades e modos de ser, valorando determinadas formas de se construir e desmerecendo outras. Pode-se pensar que as formas de se conceber são instituídas pelo discurso; afinal, os discursos "criam os objetos de que falam" (FOUCAULT, 2008). Esses discursos se constituem em saberes e estratégias de poder que constroem essas mulheres, proporcionandolhes experiências possíveis, abrindo, ainda, espaços de resistências. É no interior dos discursos e das práticas que se é confrontado com saberes e poderes e fazem-se escolhas éticas que constroem as subjetividades.

O enunciado "ser alguém na vida" carrega consigo saberes que são produzidos em um determinado tempo, marcado por ideologias que traduzem um modo de se portar no mundo que desconhece o ser como aquele que já é. Esse enunciado carrega consigo saberes e poderes que falam de nosso mundo, que afirmam que para "ser alguém na vida" é necessário ter uma profissão, ter um bom trabalho, condições materiais e que, nas entrevistas, aparecem como condições possíveis de serem adquiridas com a escolarização. No entanto, esse discurso aparece, na maioria dos casos, como algo mágico, como se o simples fato de estar na escola já implicasse "ser alguém na vida", no sentido de encaminhar as pessoas para um mundo de ascensão social. Não há, nas narrativas dessas mulheres que participaram da pesquisa, um planejamento de trajetórias para se caminhar no espaço escolar.

A frase "ser alguém na vida" também fala de uma hierarquização das pessoas: para ser alguém na vida, deve-se ter sucesso escolar, embora o percurso para tal não seja, necessariamente, expresso na maioria das narrativas: "Eu achava que queria ser professora, mas não aconteceu... (...) eu não sabia, assim, direito como que ia acontecer. Eu sabia que tinha que estudar muito, mas eu pensava que era mais fácil, aí eu comecei a não aprender, aí chegou na quarta série e eu parei. Aí acabou esse negócio de ser professora" (D. Lourdes).

Ouvir das próprias mães que para ser "alguém na vida" teriam de estudar, não garante esse caminho. Só quando se tornaram mães é que construíram esse discurso como "verdade", percebendo-o como um imperativo para a vida dos(as) filhos(as). Ser mãe significa ensinar, encaminhar, orientar para ser "alguém na vida". Significa se repensar na posição de filha que não atendeu às orientações da mãe, no sentido de "ser alguém na vida", para ser aquela que passa a compreender esse enunciado como um discurso que compõe o papel de ser mãe. Em suas narrativas, dizem que as mães falavam que elas deviam estudar, mas a atenção delas "era desviada" para outras vivências que não a escola, o que põe em xeque o alcance da educação escolar como um imperativo na vida dessas mulheres. No entanto, quando se tornaram mães, reproduziram tal discurso para os(as) filhos(as), dizendo que eles(as) deveriam "estudar para ser alguém na vida", e não "seguir o mesmo caminho" que elas de afastamento da escola. O investimento no(a) filho(a) para que construam uma história diferente no que se refere à escola é também uma forma de se verem realizadas, ou seja, de darem continuidade ao que deveriam ter vivido. Seria uma maneira de se reinventarem nos percursos traçados para o(a) filho(a).

A escola é reconhecida, em todo momento, como um caminho para o sucesso econômico e social. Apesar disso, há um desconhecimento a respeito da cultura escolar, com seus mecanismos de inclusão, exclusão, hierarquização. Enfim, parece que essa cultura de escola que exige uma dedicação em longo prazo não condiz com a cultura das mulheres e homens das classes populares que vivem as contingências de um mundo incerto e de sobrevivência diária. Essas questões parecem empurrá-los(as) para uma vida imediata. Pode-se pensar que, para eles(as), é complicado um investimento mais longo em educação, uma vez que a luta diária pela sobrevivência exige deles(as) que se pense o hoje. Nas palavras de Vanessa, "o negócio era brincar e estudar, se divertir, e cada dia continuar a ser o que era pra ser".

Compreendendo a experiência como processo de subjetivação, pode-se considerar que as experiências dos sujeitos se dão em meio a jogos de verdade, relações de poder e formas de relação consigo mesmos(as) e com os(as) outros(as) (FOUCAULT, 1984). Assim, a partir das narrativas das mulheres, é possível dizer que as experiências são construídas em meio a processos de objetivação e subjetivação vivenciados por elas, nos quais se assujeitam a saberes e a poderes historicamente construídos, mas também fazem escolhas éticas e 
contingentes diante desses processos. Segundo Foucault (2006), uma experiência é sempre uma ficção; é correlação em uma cultura, entre campos de saber, tipos de normatividade, formas de subjetivação, enfim, é algo fabricado para si mesmo, que não existe antes e que existirá depois. As pessoas se fabricam cotidianamente, em meio a jogos de verdade.

\section{ORGANIZAÇÕES FAMILIARES E ATRAVESSAMENTOS ENTRE GÊNERO E CLASSE}

As construções de classe operam nos modos de subjetivação. Ter mais ou menos condições financeiras, bem como acesso a discursos e práticas que revelam as posições de sujeito nessas construções, interfere nas relações que cada um(a) estabelece com a educação escolar. De acordo com as condições a que estão expostos, os sujeitos fazem suas escolhas e estas se diferenciam em relação às classes a que pensam pertencer. Segundo Rosemberg (2012, p. 350), as pesquisas em larga escala ressaltam que:

As diferenças no acesso e progressão escolar não são equivalentes a todos os segmentos de renda e que afetam, particularmente, os estratos de renda inferiores. Ou seja, o melhor desempenho escolar observado entre as meninas, moças e mulheres adultas do que de meninos, rapazes e homens adultos, praticamente desaparece nos níveis de renda médios e superiores.

De acordo com a autora, os melhores índices alcançados pelas mulheres na educação em relação aos homens se sustentam, inclusive quando se levam em conta outras categorias de análise como "raça"/ etnia, área urbana/área rural e regiões brasileiras. No entanto, há um atravessamento de rendimentos incidindo nessas categorias. É entre os negros/pardos, em áreas rurais e regiões brasileiras mais pobres, que se observa um melhor índice de escolarização das mulheres em relação aos homens, ou seja, são nos grupos de piores condições socioeconômicas que as mulheres se sobressaem (ROSEMBERG e MADSEN, 2011). Portanto, quanto à categoria classe, é possível perceber que esta interfere diretamente no acesso e na permanência no sistema escolar, uma vez que nos níveis de renda médio e superior a diferença entre homens e mulheres praticamente desaparece (ROSEMBERG e MADSEN, 2011; ROSEMBERG, 2012). Ou seja, há um modo de ser homem e de ser mulher atravessado por classe. A diferença de escolarização entre homens e mulheres é mais observada nos níveis inferiores de renda. Ainda, segundo Rosemberg (2012, p. 350-351):
As desigualdades de rendimento familiar, "cor"/"raça", região e local de residência, bem como geração, afetam mais intensamente a escolaridade de homens e mulheres no Brasil que as diferenças de sexo, o que faz com que o acesso e a progressão na educação das mulheres seja equivalente (mas não idêntica) aos de coetâneos masculinos.

A partir das afirmativas de Rosemberg (2012), percebe-se que o imperativo da educação escolar atinge todas as classes sociais, mas nas populares ele atua de modo diferenciado. São nelas que as diferenças de gênero operam de forma acentuada nas relações com a escola. A educação escolar, assim, concorre com outros chamados que se dão a partir dos atravessamentos de gênero. Aproximar-se mais ou menos da escola pode significar responder a esse ou a outros imperativos que se colocam na vida cotidiana dessas pessoas. Em muitos casos, esses outros imperativos fazem mais sentido e se mostram mais concretos que a escolarização. Dentre eles, questões como maternidade e constituições familiares, além das contingências de classe que distanciam as pessoas de uma vida escolar mais prolongada.

Embora gênero e classe estejam intimamente ligados aos modos de subjetivação e, com isso, dizerem das relações das participantes de pesquisa com a escola, a questão de classe parece ser uma categoria forte no que diz respeito a um distanciamento da educação escolarizada. As narrativas trazem componentes de classe e de adversidades vividas por homens e mulheres desses meios, interferindo nos seus processos de escolarização.

Dentro das construções de classe, as de gênero interferem nos modos como meninos e meninas se relacionam com a educação. Estudos como os de Dal'Igna (2005), Carvalho (2001, 2004, 2009), Pereira (2008), dentre outros, têm discutido o desempenho escolar de meninos e meninas. De uma forma geral, os trabalhos procuram romper com uma polarização dos gêneros, trazendo à baila outros componentes que, junto com este, podem estar atuando no desempenho de meninos e meninas na educação escolar. Estes seriam as construções de classe, raça, etnicidade, geração, construções familiares, dentre outros fatores.

Tais estudos apontam para gênero como uma construção social que, para além da constituição de meninos e meninas como desiguais, demonstra que a forma de avaliá-los e compreendê-los dentro do sistema escolar mostra-se igualmente diferenciada. Portanto, gênero, além de construir homens e mulheres como diferentes, o que já acarreta uma forma de se relacionar com a educação escolar de forma distinta, também constrói mecanismos de adequação e inadequação ao sistema escolar a partir do olhar generalizado do outro. Construir meninos e meninas de forma diferenciada, assim como 
avaliá-los e classificá-los também de modos diferentes, vem interferindo decisivamente na permanência ou na expulsão dos(as) mesmos(as) do sistema escolar. Essas formas são marcadas também por questões de classe.

Vanessa, Cláudia e sua mãe, D. Lourdes, retratam um pouco essas construções de classe e gênero e suas interseções com a vida escolar de seus familiares. Essas mulheres faziam parte de uma família bastante numerosa, 16 crianças e três adultos que dormiam no chão e apresentavam poucos recursos financeiros para suprir as necessidades básicas, sofrendo inclusive intervenção do Conselho Tutelar e da assistente social do bairro. Quando as crianças começaram a crescer, o envolvimento com as drogas tornou-se mais um problema a interferir na vida familiar, seja pelo uso de drogas por parte de alguns dos filhos ou pelos maridos de algumas das filhas. Questões como furtos, roubos, overdoses e prisões também foram narradas por elas, e isso atuou na constituição das subjetividades de seus membros e interferiu na educação escolar, sobretudo dos meninos. Vanessa relata, ainda, ter sido vítima de uma tentativa de estupro que a afastou da escola. Das 16 crianças da família, apenas as meninas chegaram a cursar o ensino médio. Duas delas o concluíram por meio da EJA e duas fizeram até o primeiro e o segundo ano. Uma teve uma repetência, mas continua estudando no $6^{\mathrm{O}}$ ano do ensino fundamental. As demais se afastaram da escolarização ainda nessa mesma etapa da educação.

D. Lourdes fala sobre sua "luta" para criar filhos(as), irmãos(ãs) e sobrinhos(as), sem poder contar com a ajuda do marido, que era, segundo ela, "alcoólatra": "Ele bebia, jogava e coisa assim, né? Quem bebe não consegue ficar com dinheiro por muito tempo". D. Lourdes relata também suas preocupações com um dos(as) irmãos(ãs) que apresentava "problemas mentais", exigindo dela uma atenção especial, tendo, inclusive, sido preso em decorrência de uma denúncia de tentativa de estupro:

\begin{abstract}
"Quando eu peguei as crianças, ele [o marido de Lourdes] quase que queria ir embora se eu ficasse com o Ademir. Eu tive que ter força para falar que ia ficar com o Ademir de qualquer jeito. Ele estava achando que ia ficar difícil, aí ele não queria, ele não queria reclamação dos outros. Ele achava que a gente não ia conseguir controlar o Ademir. É, porque quem vê o Ademir hoje não sabe como ele era. Ele era muito diferente. Ele aprontava muito, fazia cada coisa que só vendo. Aí o meu marido não estava dando conta, mas aí fiquei com ele de qualquer jeito.” (D. Lourdes)
\end{abstract}

Nas narrativas de D. Lourdes, a sua posição de mulher, mãe e esposa parece construída como aquela que tem de dar conta de tudo. Ajeitar o local para que as crianças possam dormir, decidir por criar as irmãs e o irmão e, inclusive, buscar as condições financeiras para o sustento da família, já que quem "bebe não consegue ficar com dinheiro por muito tempo".

Refletindo-se sobre como as experiências constroem a vida das pessoas, torna-se interessante pensar nas construções que essa família vivenciava. D. Lourdes, uma mulher, constituindo-se como a cuidadora, a provedora, a que tomava decisões acerca da família, e o marido/pai como aquele que "bebia", "jogava", "gastava o dinheiro da família", "não falava nada", "era assim muito tranquilo", e que, diante de um problema, "queria ir embora" e "não estava dando conta".

Tomando Larrosa (2014, p. 16) como inspiração para se pensar que "as palavras produzem sentidos, criam realidades e, às vezes, funcionam como potentes mecanismos de subjetivação", é possível inferir que as utilizadas por Lourdes, no ato mesmo de narrar, já a constituíram e devem ter atuado também na constituição dos membros da família. E essas palavras criaram uma polarização entre uma construção de homem e de mulher de forma antagônica. A mulher, como aquela que cuida da família e do homem que "não dava conta". Não se quer dizer com isso que nessa família as mulheres serão sempre construídas como as cuidadoras e os homens, como os desinteressados pela família. Mas, sim, que construíramse discursos que traduziam esses binarismos e que atuaram na construção dos sujeitos, inclusive podendo apresentar resistências ante tais construções. Como alerta Larrosa (2014, p. 16): "Eu creio no poder das palavras, na força das palavras, creio que fazemos coisas com as palavras e, também, que as palavras fazem coisas conosco". São forças discursivas que expõem o jogo entre o verdadeiro e o falso, e, na experiência vivida por essa família, uma das verdades era que a mulher-mãe é aquela que cuida e que, portanto, interessa-se pela educação dos filhos e filhas.

Diante das narrativas e das vivências levantadas pelas participantes da pesquisa, os componentes de classe parecem ser os fatores que mais afastam homens e mulheres do sistema escolar. As incertezas que vivenciam, suas contingências, encaminham homens e mulheres a escolherem outros caminhos para a realização pessoal que não a escola, outros imperativos de classe que se fazem presentes. Não que não haja resistências. As narrativas falaram dessas resistências, as mulheres tentaram estudar. Afastaram-se e voltaram ao sistema escolar por algumas vezes, mas as contingências culminaram por ser mais imprescindíveis que a escola.

$\mathrm{Na}$ categoria classe, os fatores que levam homens e mulheres a se afastarem da escola apresentam as construções de gênero como componentes importantes. Nas entrevistas, não houve a verbalização do privilégio de um dos gêneros para a escolarização; entretanto, pôde-se perceber que essas diferenças incidiram na aproximação 
e no distanciamento da educação escolar. De acordo com as narrativas, a gravidez parece ser um componente importante para o afastamento das mulheres da educação escola, e as questões referentes à socialização dos homens, perpassados por processos mais agressivos e de desafio à disciplina, demonstram esse afastamento. Através das entrevistas com as mulheres foi possível perceber que a representação dos homens como provedores apresenta ligações com o afastamento dos homens da escola para o mundo do trabalho ou para outras formas de aquisição de bens.

Em relação ao tratamento da família dispensado às meninas e aos meninos, as mulheres disseram não perceber diferenciações nesse aspecto. Afirmaram que meninos e meninas têm, igualmente, de estudar; no entanto, no desenrolar das narrativas, algumas representações sobre ser homem e ser mulher foram enquadrando as pessoas e posicionando-as, incidindo diretamente em sua relação com a educação escolar.

"Eu acho assim... Acho que não tinha diferença não. Do mesmo jeito que ela [a professora] intimava as meninas, ela intimava os meninos. Só que, assim, um lado era só dos meninos, as carteiras de um lado só para os meninos, e o outro lado, só as meninas, mas a matéria era a mesma, era só para não dar conversa, recadinho de namoradinho pra lá, namoradinho pra cá, porque o negócio ficava separado.” (Vanessa)

Por mais que Vanessa acreditasse que não havia diferença de tratamento dispensado aos meninos e às meninas, a própria disposição da sala já os(as) posicionava como diferentes, inclusive atentando para as questões de sexualidade como algo perigoso. Separavam-se meninos e meninas para evitar os "recadinhos de namoradinho".

D. Lourdes disse que queria que os filhos e a filhas estudassem e que não fazia diferenciações entre eles:

\footnotetext{
"Ah, eu nunca obriguei nada não, eu queria que eles estudassem, que tivessem uma profissão, que estudassem mais do que eu estudei, mais isso é deles... Tinha, assim, o Bruno, eu falava que ele podia estudar para bombeiro porque parece que é bom ser bombeiro. Ele até chegou a falar que queria ser bombeiro, mas aí foi passando e ele não estudou, nem nada. A Cláudia, eu pensei que ela podia ser uma professora, porque ela gostava de escola, tinha nota boa, eu pensei que ela podia ser uma professora, mas ela não quis. Até que ela estava indo bem, fez o segundo, mas depois parou, depois fez o supletivo e pronto. Então é isso, eu falava que era bom estudar, mas depois era com eles. Eles é que deviam escolher." (D. Lourdes)
}

Quanto à escolha para o filho, ser bombeiro, ela alegou que "parece que é bom ser bombeiro", mas não afirmou com exatidão. $\mathrm{O}$ "parece" revela que ela acredita que ser bombeiro é uma boa profissão para seu filho; no entanto, não foi categórica nessa afirmativa, sem apresentar critérios e informações para essa escolha. E, como as palavras fazem coisas conosco e funcionam como potentes processos de subjetivação (LARROSA, 2014), o filho Bruno "até chegou a falar em ser bombeiro", mas acabou não realizando esse desejo dele e da mãe.

De qualquer forma, há um investimento na escola/ escolarização como possibilidade de mudança. Reconhece-se a escola como uma instituição capaz de mudar a vida das pessoas, de proporcionar uma ascensão de classe, "no sentido de melhorar a dor de tanta gente" (MOREIRA, 2007, p. 51). No entanto, esse investimento na educação parece algo distante, difícil de ser atingido, daí a passividade em aceitar a desistência da educação escolar. D. Lourdes afirmou que "queria que eles estudassem, que tivessem uma profissão, que estudassem mais do que eu estudei"; no entanto, "eles começavam a faltar, falavam que não estavam gostando de estudar e paravam".

$\mathrm{Na}$ família de D. Lourdes, os meninos se afastaram mais precocemente da escola. O envolvimento com drogas e socialização mais ligada às violências dize também desse afastamento dos homens em relação à educação escolar. As formas de socialização dos meninos parecem colocálos em maior dificuldade para continuar na escola. Nas narrativas, não foi apontado o envolvimento das mulheres com as drogas, embora seja sabido que existem muitos desses casos. No entanto, a ligação com o consumo e tráfico de drogas pelos homens foi recorrente nos relatos de Flávia, D. Lourdes e Cláudia e indiretamente apontado nos relatos de Vanessa, Cristina e D. Cristiana.

\footnotetext{
"Quer ver? O Bruno ia bem na escola. Quando ele estava na $5^{\mathrm{a}}$ série, eles me chamaram lá e perguntaram o que estava acontecendo com o Bruno. Eu falei que não estava acontecendo nada, que estava tudo normal. Aí eles falaram que era para eu observar, porque estava acontecendo alguma coisa com ele. Que ele estava nervoso, estranho, que alguma coisa tinha. Eu conversei com ele e ele não gostou, falou que não tinha nada, que estava tudo bem, para eu deixar ele no canto dele. Aí um dia apareceu lá em casa um menino pequenininho assim, e chamou-o no portão. O Bruno foi. Aí eu estou vendo-o conversar e o menino passou um negócio pra ele. Eu dei um aperto nele e peguei uma caixa de fósforos com ele. Era droga. (...) Aí eu fui à escola, falei o que estava acontecendo, expliquei pra diretora que o menino tinha levado maconha pro meu filho e tudo. Eles ficaram assustados, aí ela pediu para eu mostrar quem era o menino. Eu fui, mostrei e tudo. E conversei com o Bruno e tudo. Mas não teve jeito." (D. Lourdes)
}

Os relatos de D. Lourdes ilustram o papel central da mulher na tarefa de cuidar e educar os filhos e filhas. Não 
apenas no depoimento expresso acima, mas em todas as narrativas colhidas para essa pesquisa, as mulheres são as protagonistas no cuidar e educar os filhos e filhas. Há um grande vazio no que concerne à participação dos homens na criação e educação destes(as). Quando Bruno apresentou um problema na escola, foi a mãe que tentou resolver. Quando ela percebeu o envolvimento do filho com as drogas, foi ela quem procurou a escola para buscar soluções para o problema. Quando tentou interagir com o menino, que na sua perspectiva estava "desviando" seu filho, ela o ameaçou de falar com a mãe dele, mesmo não a conhecendo. É como se ela estivesse revelando que educar os filhos e filhas fosse tarefa para ser resolvida de mulher para mulher.

Como já havia sido chamada para tratar de assuntos relativos ao filho em relação a uma suspeita de uso de drogas, D. Lourdes retornou à escola como que para dar uma satisfação, ao mesmo tempo em que reivindicou a instituição como instância de resolução de problemas. Mesmo que o episódio envolvendo o filho e o colega tenha ocorrido fora do ambiente escolar, D. Lourdes se dirigiu à escola para partilhar com ela o problema enfrentado com o filho. A escola, portanto, parece ser ainda um lugar que fala dos sujeitos, que procura resolver os problemas do sujeito, pelo menos no que diz respeito à manutenção das conquistas fundamentais da modernidade quanto à organização e socialização das pessoas.

\section{CONSIDERAÇÕES FINAIS}

Através das narrativas, constroem-se histórias sobre determinadas mulheres e sobre uma escola. Ao mesmo tempo, o artigo traz algumas verdades concebidas, percebendo-as como contingentes, incertas, mas verdadeiras no momento da entrevista. Relatos construídos a partir das experiências de quem narra o ocorrido, com os olhos do momento presente, ressignificando um passado e vislumbrando um futuro.

Dado o corte geracional, foi possível perceber que a educação escolar como um imperativo para as classes populares ainda é algo recente, mas potente para elas. $\mathrm{O}$ que ocorre são modos de socialização diferentes, que atuam, causando um estranhamento da escola em relação às famílias que atende, e dessas famílias em relação à escola. Não há um desinteresse pela escola, muito pelo contrário, acredita-se na importância da escola. A dificuldade está na relação que se estabelece entre os dois grupos que são atravessados por relações de poder e que, por isso, instituem verdades sobre os sujeitos, classificando-os como interessados ou desinteressados pela educação escolar.

As mulheres narraram que a educação escolar se mostrava como importante para meninos e meninas, "uma forma de ser alguém na vida" que não exprimia o gênero das pessoas. Disseram também que não percebiam tratamento diferenciado para os meninos e meninas, nem na escola, nem na família. As narrativas mostraram uma invisibilidade das diferenças. Contudo, as falas atestavam que havia, sim, diferenças na forma como meninos e meninas se colocavam em relação à educação escolar. Nos relatos, as meninas, com algumas exceções, foram mostradas como mais afeitas a esse tipo de socialização, e os meninos, com mais dificuldade de transitarem por esse mesmo espaço.

Além dessas formas escolares de construção de meninos e meninas, ficou evidente nas narrativas que as vivências na classe exigem de homens e mulheres outras posições de sujeito e que estas dificultavam uma relação mais prolongada com a escolarização. As mulheres mostravam interpelações que se relacionavam à maternidade e à constituição de família como outras formas de se construir no mundo que nem sempre parecia conciliável com a educação escolar. O posicionamento da mulher também se mostrou um complicador para os processos de escolarização, exigindo que se construísse como aquela que tem o dever de cuidar dos membros da família, mesmo que isso venha a prejudicar sua escolarização. Em relação aos homens, o papel de provedor da casa mostrou-se como uma posição de sujeito que interfere diretamente no distanciamento da educação escolar. E certas construções de masculinidade mais afeitas à violência e resistência à autoridade mostraramse como concepções que dificultaram a escolarização de homens das classes populares.

\section{REFERÊNCIAS}

CARVALHO, Marília Pinto de. Mal aluno, boa aluna? Como as professoras avaliam meninos e meninas. Estudos Feministas, Florianópolis, v. 9, n. 2, p. 554-574, 2001.

O fracasso escolar de meninos e meninas: articulação entre gênero e cor/raça. Cadernos Pagu, Campinas, v. 22, p. 247-290, 2004.

Gênero, raça e avaliação escolar. Cadernos de Pesquisa, São Paulo, v. 39, n. 138, p. 83-866, set./dez. 2009.

DAL'IGNA, Maria Cláudia. "Há diferença?” - Relações entre desempenho escolar e gênero. Dissertação (Mestrado em Educação) - Programa de Pós-Graduação em Educação, Faculdade de Educação, Universidade Federal do Rio Grande do Sul. Porto Alegre: UFRGS, 2005. 167 p.

FOUCAULT, Michel. História da sexualidade II: o uso dos prazeres. Tradução de Maria Thereza da Costa Albuquerque. 13. ed. Rio de Janeiro: Edições Graal, 1984. Vol. 2. 333 p.

1993.

Microfísica do poder. Rio de Janeiro: Edições Graal,

Ética, sexualidade, política. Ditos e Escritos. 2.ed. Rio de Janeiro: Forense Universitária, 2006. Vol. 5. 
A arqueologia do saber. Tradução de Luiz Felipe Baeta Neves. 7. ed. Rio de Janeiro: Forense Universitária, 2008. 236 p.

A ordem do discurso: aula inaulgural no Collége de France, pronunciada em 2 de dezembro de 1970. Tradução de Laura Fraga de Almeida Sampaio. 20. ed. São Paulo: Edições Loyola, 2010. 79 p.

LARROSA, Jorge. Tremores: escritos sobre experiência. Tradução de Cristina Antunes e João Wanderley Geraldi. Belo Horizonte: Autêntica, 2014. 175 p.

PEREIRA, Fábio Hoffmann. Encaminhamentos a recuperação paralela: um olhar de gênero. Dissertação (Mestrado em Educação) - Faculdade de Educação, Universidade de São Paulo. São Paulo: Universidade de São Paulo, 2008, 109 p.
ROSEMBERG, Fúlvia. Mulheres educadas e a educação de mulheres. In: PINSKY, Carla Bassanezi; PEDRO, Joana Maria (Org.). Nova História das Mulheres. São Paulo: Contexto, 2012, p. 333-359.

ROSEMBERG, Fúlvia; MADSEN, Nina. Educação formal, mulheres e gênero no Brasil contemporâneo. In: BARSTED, Leila Linhares; PITANGUY, Jacqueline (Org.). O Progresso das Mulheres no Brasil 2003-2010. Rio de Janeiro: Cepia; Brasília: Onu Mulheres, 2011. p. 390-434.

Recebido em 30-08-2015.

Aprovado em 21-10-2016. 